\title{
RETERRITORIALIZAÇÃO DOS AFETOS EM TEMPOS DE PANDEMIA
}

\author{
RETERRITORIALIZATION OF AFFECTS IN PANDEMIC TIMES
}

\author{
Luana Garcia Feldens Fusaro ${ }^{1}$ \\ Juliana Garcia Feldens ${ }^{2}$
}

\begin{abstract}
Resumo: Este texto pretende provocar uma reflexão sobre como as medidas de isolamento social, decorrentes da pandemia da Covid-19, podem atravessar a dimensão dos corpos a partir de processos de reterritorialização dos afetos no presente. Utilizando a noção espinosiana de hecceidade, trabalhada por Deleuze e Guattari, em que o corpo é o conjunto de seus movimentos, repousos e graus de potência dos afetos, busca-se aqui pensar de que maneira as restrições físicas e sociais da pandemia podem alterar as noções espaçotemporais individuais e coletivas.
\end{abstract}

Palavras-chave: Afetos; corpos; pandemia.

\begin{abstract}
This text intends to provoke a reflection on how the measures of social isolation, resulting from the pandemic of Covid-19, can cross the dimension of the bodies through processes of re-territorialization of the effects in the present. Using the Spinosian notion of hecceity, worked on by Deleuze and Guattari, in which the body is the set of its movements, rests and the degrees of power of affections, we try to think here of how the physical and social restrictions of the pandemic can change as individual and collective spatio-temporal notions.
\end{abstract}

Keywords: Affections; bodies; pandemic.

\section{Dimensões suspensas}

O ano de 2020 trouxe o prelúdio da propagação do vírus SARS-COV-2, que causa a Covid19. Detectado inicialmente na China no final de 2019, o vírus se espalhou rapidamente e, em menos de três meses, pessoas foram infectadas em todos os continentes do planeta, levando a Organização Mundial da Saúde (OMS) a declarar estado de pandemia. Embora comparado com a Gripe Espanhola do início do século XX e a outras epidemias históricas, o cenário logo se demonstrou inédito por se tratar de uma doença de alto nível de contágio, conciliada ao contexto globalizado contemporâneo. A gravidade da pandemia gerou medidas institucionais e governamentais que provocaram uma ruptura repentina dos hábitos e fluxos cotidianos de toda a humanidade. Mesmo os negacionistas ou aqueles que vivem nas regiões mais remotas do planeta foram atingidos de alguma forma, seja pela ruptura na ordem das ações práticas, ou nas diversas instâncias das relações afetivas, de espaço e de tempo. A pandemia relançou às discussões e pesquisas a noção de tempo presente, assim como as mudanças provocadas pelo "novo normal" fazem refletir, igualmente, sobre a condição de corpo e afeto. Esse contexto inédito não só gerou a paralisação de grande parte das atividades usuais, como também alterou a nossa noção de temporalidade, especialmente por ter como um ponto importante a ideia de risco associada à proximidade com a morte. Isso porque, as afecções voltadas para o futuro precisam de uma dilatação do tempo para se sustentarem e, para nós humanos, esta noção se constrói em relação à perspectiva do tempo que se tem, ou seja, o tempo de vida.

A orientação para o distanciamento social implicou em uma desterritorialização de atividades, restrições de deslocamentos, limitações físicas, geográficas, nas atividades comerciais,

\footnotetext{
${ }^{1}$ Pontifícia Universidade Católica de São Paulo - PUC/SP, São Paulo.

${ }^{2}$ Pontifícia Universidade Católica de São Paulo - PUC/SP, São Paulo.
} 
relações sociais, assim como na forma e intensidade como utilizamos as tecnologias digitais. Embora a Organização Mundial da Saúde tenha transmitido orientações gerais, cada país gerenciou as suas próprias condutas, políticas e regras de restrição. No Brasil, cerca da metade da população aderiu ao distanciamento social ${ }^{3}$ nos primeiros meses. Os que o fizeram, transferiram suas atividades de trabalho para a versão home office, estudantes passaram a ter aulas remotas, outros ficaram impossibilitados de exercer suas profissões, e nesse cenário, algumas pessoas se viram mais ociosas, enquanto outras sobrecarregadas. O rompimento das fronteiras entre casa e escritório, tarefas profissionais e domésticas, e da divisão temporal para as demandas pessoais, familiares e ocupacionais, puseram em estado caótico a setorização da vida de muitas pessoas.

Independentemente de cada experiência particular, a pandemia produziu efeitos também no âmbito coletivo nos laçando de volta ao presente. Inicialmente porque ela nos colocou em estado de urgência, provocando uma imensurável ruptura de algumas das lógicas que pareciam estáveis na contemporaneidade.

\section{O medo do futuro}

A retomada dos afetos do presente, só é possível porque há antes uma noção sobre como os afetos do futuro vinham agindo sobre nossas vidas. Um dos primeiros teóricos do início do século XXI que repensou nossa relação com o futuro foi Nikolas Rose (2013). Em seu livro "A política da própria vida", Rose define nosso presente como uma dimensão povoada por clichês do futuro, construídos, sobretudo, a partir das ciências da vida, da biomedicina e da engenharia genética. Isso significa que vivemos em uma sociedade que controla o presente baseada em ameaças futuras, dentro de uma lógica produtiva que atua nas mais variadas instâncias da vida social, ou seja, os afetos relacionados ao futuro vinham orientando as nossas ações no presente, sobretudo, medo e esperança.

Spinoza entende que a esperança é a alegria inconstante, enquanto o medo é a tristeza inconstante, sendo que ambas são originadas "da ideia de uma coisa futura ou passada de cuja ocorrência até certo ponto duvidamos." (SPINOZA, 2018, p. 347). Isso porque, para esses afetos existirem é preciso que haja uma expectativa futura de algo que venha de referências préconstituídas, ou seja, a partir de afecções do passado, que atuem sobre o presente. A partir desta óptica é que se constitui uma noção de risco aplicada aos mais variados setores da sociedade, como saúde, segurança, economia, trabalho, etc. de diversas formas. A ideia de risco pode ser pensada pelo viés da imprevisibilidade da vida, pela nossa disposição aos movimentos, à mudança e ao quanto nos propomos arriscar. No entanto, estamos aqui falando sobre uma lógica de risco que vinha conduzindo a vida contemporânea, guiada pelas instituições sociais.

A transição do século XIX para o século XX trouxe para a noção de risco outra perspectiva com a introdução das ciências estatísticas, cujos cálculos de probabilidade poderiam estimar, de forma aproximada, chances e efeitos de algumas escolhas e apostas. Essa capacidade de mensurar o perigo passou a afetar as decisões tomadas no presente de outra forma, amarrando ainda mais à relação das expectativas com o futuro. Isso produziu uma grande transformação no século XX em relação ao comportamento no âmbito individual e coletivo. No entanto, esta lógica de conduta no presente, baseada no medo e na esperança, já permeava outros campos. Por muitos séculos, ela já vinha sendo pautada através de preceitos morais que apresentam como consequência dois redutíveis caminhos: a punição ou a recompensa. Esta ideia compõe não só uma vigilância vertical, mas uma moralidade estruturada de forma horizontal, reproduzida socialmente. A ciência efetiva a mesma lógica sob as nossas condutas,

\footnotetext{
${ }^{3}$ Índice de Isolamento Social divulgado em abril de 2020 pela empresa In Loco com base na analisa de dados de mais de 60 milhões de dispositivos móveis em todo o Brasil.
} 
mas se pautando na relação causa-efeito. Assim, quando uma pessoa decide assumir um risco, existe nesta opção algum tipo de cálculo de custo benefício.

Nosso presente passou a ser colonizado por expectativas em que a associação do risco com o comportamento, afeta um campo moral. Nesse sentido, se cria a ilusão de que quanto mais cálculos sobre as variáveis dos sistemas que compõem um contexto, mais chances de se proteger ou ser vitorioso. Muitas das questões que agem sobre o medo se dão no campo da imaginação, da especulação, não do real. Para o medo ter efetividade é necessário criar um objeto de perigo, e a ameaça se torna capaz de justificar a necessidade de uma ação preventiva, pautada antes em um embasamento emocional, do que racional. Por isso, o medo pode ser um sentimento tão perigoso, capaz de produzir ações e reações irracionais, impulsivas e violentas.

O neoliberalismo também se especializou em produzir novas formas de afetos, agenciados pelo futuro, como uma estratégia de captura para o consumo. O livre mercado incentiva não somente a circulação de produtos de necessidade básica e os incalculáveis objetos de desejo acoplados aos sentimentos de prazeres que eles prometem ser revertidos, mas também se cria de outro tipo de consumo relacionado ao risco. Por exemplo, o medo de ser assaltado nos faz colocar cercas elétricas em casa, pela esperança de estarmos seguros. A ideia é que, sem cerca elétrica, a probabilidade de um assaltante escolher a sua casa é maior do que a dele escolher a casa do vizinho que tem cerca. No entanto, o assalto é só uma ideia, ele de fato não está ocorrendo e pode ser que nunca ocorra. É o medo de um possível assalto, lá no futuro, que age enquanto um afeto no presente, e assim se torna real. $\mathrm{O}$ mesmo se dá ao contrário. Na esperança de ganhar muito dinheiro, por exemplo, milhares de pessoas compram bilhetes de loteria, mesmo que se prove a imensa improbabilidade deste ser sorteado. A sensação de prazer que a ideia de ter muito dinheiro produz, já é convincente e real o suficiente, porque um afeto, mesmo que no campo do imaginário, sempre é real. "Só por imaginarmos que uma coisa tem algo semelhante ao objeto que costuma afetar a Mente de Alegria ou Tristeza, ainda que isso em que se assemelham não seja a causa eficiente destes afetos, contudo a amaremos ou odiaremos". (SPINOZA, 2018, p. 263).

Os efeitos do neoliberalismo sobre os afetos referentes ao futuro foram adaptados em ressonância à evolução da tecnologia digital nas últimas décadas, que se agregaram às práticas sociais e de mercado, passando a construir ainda novas relações com o futuro. As relações sociais no ambiente digital foram sendo constituídas não apenas nos dispositivos, mas também pelos dispositivos, à medida que os mecanismos de controle se apropriavam deles, através da coleta e análise de dados pessoais, configuração de algoritmos e estratégias de modulação e indução. Tendo em vista que a captura afetiva, ou biopolítica dos afetos, se dá por meios que estabelecem situações repetitivas e de familiaridade, estes dispositivos buscam construir e configurar territórios existenciais, organizando as subjetividades. Assim, este sujeito não só é tratado enquanto potencial consumidor, como ele também passa a ser agenciado - e agenciar a si mesmo - como produto. Estas condutas compõem os nossos afetos e as nossas cartografias territoriais. O medo e a esperança contaminam tanto as emoções, que ofuscam nossa percepção em relação aos afetos que permeiam as relações com o presente e, consequentemente, com a percepção da presença do corpo na sua multiplicidade.

\section{Corpo e pandemia}

A propagação do vírus também carrega afecções de medo - de sofrimento, da morte e de prejuízos financeiros -, assim como afecções de esperança - de sobreviver, ressocializar e retomar hábitos queridos -, mas trata-se de uma circunstância extraordinária em que a ameaça é real, comprovada cientificamente, em curso, produzindo estimativas concretas das quais ações imediatas geram consequências em curto prazo. A forma como a vida estava articulada, na 
relação com o medo e a esperança, agenciava esses afetos a partir de expectativas no futuro, pautadas em promessas, ameaças ou discursos especulatórios.

No caso da pandemia o presente está sendo mapeado simultaneamente ao seu desdobramento, dentro dos padrões de comportamento. Voltamos nossa atenção para pesquisas, especialistas, dados científicos, prática que vinham perdendo espaço por conta da competitividade da comunicação expressa nos meios digitais. Com a pandemia, voltamos a dar atenção à mídia tradicional, que no Brasil andava relativamente desacreditada. Percebemos que precisávamos de informações respaldadas para poder nos proteger, que era preciso olhar para o presente, e assim, nos vimos obrigados a construir novos territórios.

A pandemia dada enquanto acontecimento, não no sentido factual de entendimento comum da expressão, mas no conceito deleuziano, desencadeou um circuito de potências novo. Na Lógica do Sentido (1974), o autor recorre à perspectiva estoicista, rompendo a lógica aristotélica da identidade, para construir uma ideia de acontecimento relacionada ao que dele se faz.

O acontecimento não é o que acontece (acidente), ele é no que acontece o puro expresso que nos dá sinal e nos espera. Segundo as três determinações precedentes, ele é o que deve ser compreendido, o que deve ser querido, o que deve ser representado no que acontece [...]. (DELEUZE, 1974, p. 152)

O acontecimento não é o ocorrido, pois nele sempre há algo que não para de começar e não para de acabar. Ele é inesgotável em si, um gerúndio, que carrega a potência de ser atualizado nele mesmo, porque há uma força inexaurível de repetição no acontecimento, compondo uma espécie de circuito do desejo intensivo. Por isso, esta noção está mais relacionada ao corpo "que quer agora não exatamente o que acontece, mas alguma coisa no que acontece, alguma coisa a vir de conformidade ao que acontece, (DELEUZE, 1974, p. 152)".

O corpo, no acumulado de sua multiplicidade e de seus afetos, vai muito além da compreensão da razão lógica. Nele agem os acontecimentos, seus devires e singularidades. Voltarse para os afetos do presente implica, assim, em uma reterritorialização do corpo, não apenas como matéria orgânica que compõe o indivíduo, mas o corpo enquanto dimensional, uma hecceidade 4 . Assim, Deleuze e Guattari consideram duas dimensões propostas por Spinoza ao afirmar que:

Um corpo não se define pela forma que o determina, nem como substância ou sujeito determinados, nem pelos órgãos que possui ou pelas funções que exerce. No plano de consistência, um corpo se define somente por uma longitude e uma latitude: isto é, pelo conjunto dos elementos materiais que lhe pertencem sob tais relações de movimento e de repouso, de velocidade e de lentidão (longitude); pelo conjunto dos afectos intensivos de que ele é capaz sob tal poder ou grau de potência (latitude). (Deleuze, Guattari, 2012, p. 49).

A noção de hecceidade proposta por Deleuze e Guattari está atrelada a esse corpo como um modo de individuação que não se refere a uma pessoa ou substância, mas à relação das variações de movimentos e de intensidades que atuam nele. Mesmo a perspectiva de individuação ainda se dá referente a um corpo aberto, ou seja, suscetível aos encontros e afetos. O corpo é sempre uma instabilidade. Voltar-se para o corpo, no presente, significa pensá-lo enquanto movimento, não no sentido de deslocamento entre dois ou mais pontos, mas em qualquer dimensão, seja uma dilatação, expansão, acontecimento ou, como propunha Bergson ${ }^{5}$,

\footnotetext{
${ }^{4}$ Hecceidade é um termo da filosofia escolástica medieval, primeiramente cunhada por Duns Scotus, que denota a características particulares, individual, o que distingue um ente de todos os outros.

${ }^{5}$ Conceito de Henri Bergson descrito em "Duração e simultaneidade".
} 
uma duração. É nesse sentido também que devemos pensar seus graus de potência, não por uma escala linear, mas a partir de suas possíveis inconstâncias. "Uma hecceidade não tem nem começo nem fim, nem origem nem destinação; está sempre no meio. Não é feita de pontos, mas apenas de linhas. Ela é rizoma". (DELEUZE. GUATTARI, 2012, p. 53).

A relação de latitude e longitude compõe uma das mais famosas frases de Spinoza: "O fato é que ninguém determinou, até agora, o que pode o corpo [...]". (SPINOZA, 2018, p. 241). Entendendo que a estrutura de um corpo é a composição de suas relações é que Deleuze transforma a afirmação de Spinoza em questão, perguntando o que pode ou não um corpo, para falar sobre a natureza dos limites de afetar e ser afetado.

Dentro deste cenário de pandemia somos provocados a pensar quais longitudes e latitudes podem estar em ressonância com as desterritorializações que atravessaram os mais diversos contextos individuais e coletivos. Quais tipos de velocidades e potências a quebra das nossas rotinas de estudos, trabalhos, lazeres e práticas cotidianas, nos produziram? De que forma será que a ruptura dessas rotinas alterou as nossas dimensões e coordenadas?

Todo e qualquer território físico que utilizamos ou passamos também criam sentidos em nossos territórios existenciais. Porém os territórios existenciais não se restringem aos territórios físicos. Tudo que nos atravessa compõem a organização de microterritórios afetivos. Desta forma, a alteração dos nossos espaços físicos e de circulação criam novos mapas de afetos, e o mesmo ocorre em relação às restrições sociais. Ora, se os afetos sempre se dão no corpo, a partir dos encontros com outros corpos, sejam eles de qualquer natureza - pessoas, animais, coisas, plantas, vento e etc. - ao mudarmos as dinâmicas em que esses encontros se estabelecem, consequentemente, isso irá incidir nas nossas composições e na multiplicidade que somos. Só a quebra possibilita a recomposição. Uma multiplicidade "não se dividi, não perde nem ganha dimensão alguma sem mudar de natureza.” (DELEUZE. GUATTARI, 2012, p. 34).

As coordenadas destas dimensões estão constantemente em agenciamento no corpo, por isso,

A questão não é a da organização, mas da composição; não é do desenvolvimento ou da diferenciação, mas do movimento e do repouso, da velocidade e da lentidão. A questão é a dos elementos e partículas, que chegarão ou não rápido o bastante para operar uma passagem, um devir ou um salto sobre um mesmo plano de imanência pura. (DELEUZE. GUATTARI, 2012, p. 42)

Sabemos que as mesmas experiências atuam de formas diferentes na singularidade de cada pessoa, ainda que se trate de um fenômeno comum a todos. Para grande parte das pessoas o distanciamento social não significou estar completamente sozinho, mas isolado com aqueles com quem dividem casa, seja família ou amigos. Somam-se a isso as incontáveis possibilidades de comunicação, distração e interação viabilizadas pelos dispositivos digitais, sobretudo através das redes sociais. Ainda assim, esta alteração de ciclo social traz consigo um leque diferente de afetos, pelo menos dos afetos que antes poderiam ser mais recorrentes. Spinoza afirma que somos seres relacionais e nesse sentido é que a construção da nossa uma autoimagem enquanto indivíduo se dá no que difere a nossa singularidade das demais e a partir de como nos percebemos em relação aos outros. Não se trata aqui de distinguir a qualidade destes afetos em termos de bons ou ruins, ou positivos e negativos, estamos apenas refletindo sobre as intensidades e movimentos que os acontecimentos podem nos produzir enquanto afetos.

Deleuze e Guattari trazem a noção de "plano de consistência" ou "plano de composição" para pensar a territorialização dos afetos. Desta forma, os autores sugerem duas interpretações para a ideia de plano. A primeira, enquanto estrutura ou gênese de natureza oculta, como a analogia de que um quadrado está para um cubo, sendo que no plano só é possível ver uma 
face, uma parte do todo. Entretanto, vamos nos ater a segunda concepção que entende o plano como uma dimensão em que,

Nada se desenvolve, mas coisas acontecem com atraso ou adiantadas, e formam
esse ou aquele agenciamento de acordo com suas composições de velocidade.
Nada se subjetiva, mas hecceidades formam-se conforme as composições de
potência ou de afectos não subjetivados. (DELEUZE, GUATTARI, 2012, p. 58)

O plano de consistência pode ilustrar estes novos territórios que a condição pandêmica nos obrigou a produzir. Isso porque são pensados justamente dentro de uma perspectiva do movimento, em que as coisas não estão planificadas de forma fixa, e sim, dentro de uma perspectiva dimensional, assim como o a malha espaço-tempo proposta por Einstein ${ }^{6}$, que existe em todos os ângulos, direções e posições imagináveis do universo. "É um plano cujas dimensões não param de crescer com aquilo que se passa, sem nada perder de sua planitude." (DELEUZE; GUATTARI, 2012, p. 58).

A latitude, ao se constituir pelos graus de potência, não pode ser pensada como uma medida extensiva, mas intensiva, assim como a soma das temperaturas. Quando juntamos um balde d'água a $20^{\circ} \mathrm{C}$ com outro de $20^{\circ} \mathrm{C}$, não teremos um grande balde com $40^{\circ} \mathrm{C}$. Assim, "se intensidades de calor não se compõem por soma, é porque devem ser acrescentados seus respectivos sujeitos, os quais impedem justamente o calor do conjunto de devir maior." (DELEUZE; GUATTARI, 2012, p. 40). As longitudes também não se constituem em medidas exatas, considerando que as velocidades e repousos se dão de formas variáveis em um tempo relativo.

\section{Sobre o tempo}

Um calendário, um relógio, uma balança, uma trena e etc. são ferramentas que estabelecem medidas de tempo-espaço inventadas, possibilitando convenções compreensíveis, a partir das quais construímos nossas territorialidades, e nada disso está separado do que somos.

"Você tem a individuação de um dia, de uma estação, de um ano, de uma vida (independentemente da duração); de um clima, de um vento, de uma neblina, de um enxame, de uma matilha (independentemente da regularidade)." (DELEUZE. GUATTARI, 2012, p. 51).

Deleuze e Guattari discorrem sobre duas formas conhecidas para se pensar o tempo. $\mathrm{O}$ Cronos é tempo matemático, constituído a partir das medidas simbólicas, cronológicas ou cronométricas, em que definimos a noção de horas, de dias, anos, distâncias, e as suas relações com a velocidade, como quilômetros por horas, metros por minutos, etc. A outra forma de temporalidade é o Aion, que se refere a um tempo flutuante, constituído dentro das individuações, das variações de movimentos e intensidades das hecceidades, do acontecimento, e do devir puro. Sendo assim, o plano de consistência se estabelece com o Aion.

Embora a percepção humana sempre se dê na oscilação e na relação entre Cronos e Aion, as condições impostas pela pandemia colocam a noção de tempo em uma condição diferente, talvez em suspensão, por estar em ressonância com a quebra de um fluxo que a antecedia. Neste contexto, "um dia mais curto ou um dia mais longo não são extensões propriamente ditas, mas graus próprios da extensão como há graus próprios do calor, da cor, etc.” (DELEUZE. GUATTARIE, 2012, p. 39). Assim, nossa perspectiva de tempo não é fixa nem linear, é sempre rizomática. Na pandemia, as ruas ficaram mais vazias, as pessoas passaram a evitar contato físico, a usar máscaras, aglomerações foram dispersas, atividades escolares suspensas, lojas fechadas, atividades culturais canceladas. Os modos de vida pré-pandêmico foram desterritorializados, o que não quer dizer

\footnotetext{
${ }^{6}$ Albert Einstein, físico alemão criador da Teoria geral da relatividade.
} 
destruídos, ou extintos, mas aquela ideia comum de "voltar ao normal", já não cabe mais, pois a experiência não retrocede, ela avança e produz sempre novos modos.

O fato é que qualquer processo de desterritorialização está embricado em uma reterritorialização. O plano de consistência, assim como as hecceidades no corpo, está sempre ativo em níveis inconstantes de agitação, velocidades e potências, vivo, rizomático, singular na sua multiplicidade, mas também em imanência, pois "as multiplicidades se definem pelo fora: pela linha abstrata, linha de fuga ou desterritorialização segundo a qual elas mudam de natureza ao se conectarem às outras." (DELEUZE. GUATTARI, 2007, p. 17).

Embora a pandemia possa nos trazer uma sensação de subtração, considerando as privações que atingiram os mais diversos setores da vida social, a experimentação de novos afetos e acontecimentos compõe como soma crescente nas dimensões da nossa multiplicidade, visto que, o plano de consistência é crescente segundo o número de conexões que se estabelecem nele (DELEUZE. GUATTARI, 2007). Talvez a dificuldade em percebermos este cenário como possibilidade de potência dos afetos, esteja atrelada a uma ideia de que tendemos a relacionar a soma, o crescimento, apenas a estímulos que envolvem afetos alegres, vindo de encontros alegres. Temos uma tendência a relacionar a noção de felicidade a uma ideia romântica e jogá-la para o futuro como um destino final, ignorando os afetos que produzem sentimentos de felicidade no acontecimento, impulsionados pelo devir. Se apenas deslocarmos esta perspectiva, podemos perceber que a felicidade está no acontecimento, e sendo assim, ela não transita com o risco, porque ela está no presente.

Tornamo-nos uma sociedade mimada, egoica, que tenta negar a morte e que não quer correr riscos, mas inevitavelmente tudo é risco. Não existe controle sobre o futuro por mais precisas que possam ser nossas estimativas e planejamentos. Existe um fluxo vida que sempre nos escapa, que está sempre deixando de ser, que já não é mais, e já não é mais. Um ótimo exemplo disso é justamente a pandemia a que estamos nos referindo, um evento imprevisível, que produziu tantos acontecimentos que pouco poderíamos ter imaginado.

Se entendermos que o passado é algo que já não está, e que o future é algo que nunca se alcança - pois se alcançado vira passado - o presente é tudo o que se pode. Nesse sentido, os afetos sempre se dão no presente, mesmo o medo e a esperança do futuro só existem porque são sentidos no presente, assim como a hecceidade, o esforço e o devir. O presente, que se dá nos planos de consistência e suas dimensões no emaranhado rizomático dos afetos. Da mesma forma, as memórias e lembranças de fatos ocorridos em momentos anteriores só existem como pensamento agindo no presente, relacionadas a todas as dimensões e contextos que estiveram implicados a este, dentro das multiplicidades que compõem a singularidade da pessoa que as pensa. Assim, as questões provocadas pela pandemia se referem a afetos do presente agenciados no presente.

É possível que a Covid-19 nos deixe entre suas heranças uma reconexão com o presente, que tenhamos mais habilidades para redesenhar territórios e estejamos mais abertos para os acontecimentos. É possível que isso represente um desdobramento no âmbito dos nossos afetos e modos de vida, ou que cresça um entendimento sobre a ilusão do controle e, desta forma, nos apegarmos menos aos afetos de medo e esperança sob o futuro, optando por mais desfrute nos afetos do presente. Lembremos, tudo é risco.

\section{Referências}

DELEUZE, Gilles. Lógica do Sentido. Tradução de Luiz Roberto Salinas Fortes. São Paulo: Perspectiva; Ed. da Universidade de São Paulo, 1974. 
DELEUZE, Gilles. GUATTARI, Félix. Mil Platôs: capitalismo e esquizofrenia, v. 1. Tradução de Aurélio Guerra Neto e Celia Pinto Costa. 1. ed. São Paulo: Ed. 34, 1995. 5. reimp., 2007.

DELEUZE, Gilles. GUATTARI, Félix. Mil Platôs: capitalismo e esquizofrenia, v. 4. Tradução de Suely Rolnik. 2. ed. São Paulo: Ed. 34, 2012.

SPINOZA, Benedictus de. Ética. Tradução de Grupo de Estudos Espinosianos; coord. Marilena Chauí. 1. ed. 1. reimp. São Paulo: Editora da Universidade de São Paulo, 2018.

ROSE, Nikolas. A politica da própria vida: biomedicina, poder e subjetividade no Século XXI. São Paulo: Ed. Paulus, 2013.

\section{Sobre as autoras}

Luana Garcia Feldens Fusaro é graduada em Comunicação Social - Jornalismo pela Universidade Tiradentes (UNIT), mestra pelo Programa de Pós-Graduação em Antropologia da Universidade Federal de Sergipe (UFS), doutoranda do Programa de Pós-Graduação em Comunicação e Semiótica da Pontifícia Universidade Católica de São Paulo (PUC-SP).

E-mail: luafeldens@gmail.com.

Juliana Garcia Feldens é graduada em Comunicação das Artes do Corpo pela Pontifícia Universidade Católica de São Paulo (PUC-SP) e mestranda do Programa de Pós-Graduação em Comunicação e Semiótica da Pontifícia Universidade Católica de São Paulo (PUC-SP).

E-mail: juliafeldens@gmail.com. 